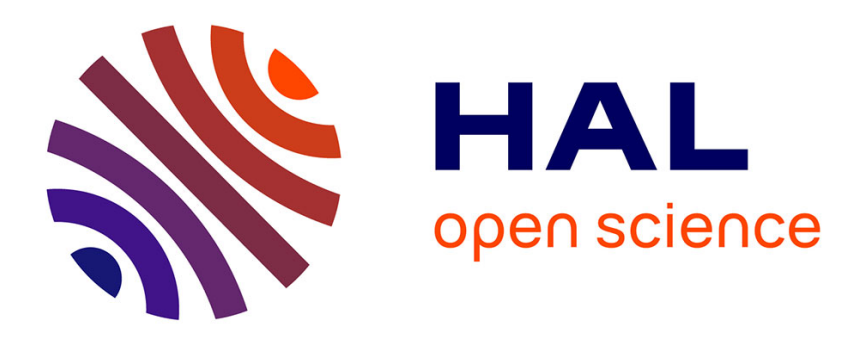

\title{
On a relation between percolation theory and the elasticity of gels \\ P.-G. de Gennes
}

\section{To cite this version:}

P.-G. de Gennes. On a relation between percolation theory and the elasticity of gels. Journal de Physique Lettres, 1976, 37 (1), pp.1-2. 10.1051/jphyslet:019760037010100 . jpa-00231221

\section{HAL Id: jpa-00231221 https://hal.science/jpa-00231221}

Submitted on 1 Jan 1976

HAL is a multi-disciplinary open access archive for the deposit and dissemination of scientific research documents, whether they are published or not. The documents may come from teaching and research institutions in France or abroad, or from public or private research centers.
L'archive ouverte pluridisciplinaire HAL, est destinée au dépôt et à la diffusion de documents scientifiques de niveau recherche, publiés ou non, émanant des établissements d'enseignement et de recherche français ou étrangers, des laboratoires publics ou privés. 


\title{
ON A RELATION BETWEEN PERCOLATION THEORY AND THE ELASTICITY OF GELS
}

\author{
P. G. DE GENNES \\ Collège de France, 75231 Paris Cedex 05, France
}

(Reçu le 15 septembre 1975, accepté le 31 octobre 1975)

\begin{abstract}
Résumé. - On établit une relation entre la conductance $\Sigma$ d'un réseau aléatoire de résistances avec une fraction $p$ de conductances non nulles, et le module d'élasticité $E$ d'un gel obtenu par polymérisation d'unités $z$-fonctionnelles ( $p$ étant ici la fraction de liaisons qui ont réagi).
\end{abstract}

Abstract. - We compare the macroscopic conductance $\Sigma$ of a resistor network with a fraction $p$ of conducting links, and the elastic modulus $E$ of a gel obtained by polymerization of $z$-functional units ( $p$ being the fraction of reacted bonds).

Consider a Bravais lattice with nodes $(i, j, \ldots)$ connected by conductances $\sigma_{i j}$, the voltages being $V_{i}, V_{j} \ldots$ The entropy source is

$$
T \stackrel{\circ}{S}=\frac{1}{2} \sum_{i j} \sigma_{i j}\left(V_{i}-V_{j}\right)^{2}
$$

Minimization of $T \stackrel{\circ}{S}$ with respect to $V_{i}$ leads to the Kirchhoff equation. When $\sigma_{i j}$ connects only neighbouring sites, and is a random variable with values $\sigma$ (probability $p$ ) and 0 (probability $1-p$ ) the system may show a macroscopic conductance $\Sigma$ (such that $T \stackrel{\circ}{S} / \mathrm{cm}^{3}=\Sigma E^{2}$, where $E$ is the average field). $\Sigma$ has been investigated by Last and Thouless [1] : near the percolation threshold $p_{\mathrm{c}}$, it is apparently of the form :

$$
\Sigma=\text { const. } \delta p^{\mu} \quad\left(\delta p=p-p_{\mathrm{c}}\right)
$$

where $\mu$ cannot be related directly to other critical exponents of the percolation problem, for which a renormalization group approach is now available [2-3]. But the analogue of $\Sigma$ occurs in many physical problems :

a) with magnetic atoms, coupled by ferromagnetic exchange integrals $\sigma_{i j}$, at low temperatures, $V_{i}$ being a tilt angle for the moment $(i)[4,5]$;

b) with superconducting grains, coupled by Josephson junctions, of critical current $\sigma_{i j}\left(V_{i}\right.$ being the phase of the order parameter on grain $i$ ) [6]. In the present note we add one other member to the list;

c) polycondensation of $z$-functional monomers, with a fraction $p$ of reacted bonds [7]. For the moment we assume that the monomers are point-like, and occupy all sites on a $d$-dimensional Bravais lattice (the number of neighbours of one site being $z$ ). Here $V_{i}$ represents one component (say $X_{i}$ ) of the elastic displacement of the $i$ th monomer from its rest position. In cases $(a), b)$, and $c)$ ) the analogue of the minimization functional $T S$ is an elastic energy (assumed to be Hookean). The analogue of $\Sigma$ is a LandauLifshitz rigidity $A$ [8] (case $a$ )), a superfluid density $\rho_{\mathrm{S}}($ case $b)$ ), and an elastic modulus $E$ (case $\left.c\right)$ ). All these quantities should follow eq. (2) with the same exponent $\mu(d)$.

The statement for case $c$ ) is rigourous only with a lattice model of gelation- or for the inverse processes of crystal degradation by mobile agents [9]. But it may plausibly be extended to more general situations where (i) the starting point is a liquid of monomers (rather than a crystal) and (ii) the connection between $z$-functional monomers is not through a single bond, but rather through a flexible chain of finite length (e.g. : adipic acid [10]). Of course the $\delta p$ interval where eq. (2) holds will depend on the problem : the zero volume extrapolation invented by Stockmayer [11] tends to make it small [12]. We know that for $d \geqslant 6$ the percolation problem on Bravais lattices is not qualitatively different from the behaviour of tree-like structures (mean field behaviour) [3], [13]. Conductance properties of trees have been calculated exactly : (i) the conductance $\bar{\sigma}_{0 \infty}$ from one point to infinity behaves like $\delta p^{2}$ [14]. (ii) For the gel problem a related parameter is the number $G$ of active network chains per monomer and this is proportional to $\delta p^{3}$ [15]. It is common belief that $E$ is proportional to $G$. This is probably correct, but more accurately stated in terms of a variational calculation, as follows. Starting from one realization of the system, we first delete all dangling ends; we are then left with active chains 
connecting at certain nodes $n, m \ldots$ We can then rewrite $T S$ as

$$
T \stackrel{\circ}{S}=\sum_{(n, m)} \sigma_{n m}\left(V_{n}-V_{m}\right)^{2}
$$

where $\sigma_{n m}$ is the conductance of one chain connecting $n$ and $m$, and the sum $\sum$ is over all active chains. We have $\sigma_{n m}=\sigma / N_{(n m)}$ where $N_{(n m)}$ is the number of bonds along the chain. As a variational voltage distribution we choose $V_{n}=\mathbf{E} . \mathbf{R}_{n}$ where $\mathbf{R}_{n}$ is the position of the node $n$. Inserting this into (3) we are led to calculate averages :

$$
\left\langle\left(R_{n}-R_{m}\right)^{2}\right\rangle \sim N_{n m} .
$$

Eq. (4) holds for large $N_{n m}$ (i.e. near $p=p_{\mathrm{c}}$ ) even if there is more than one chain connecting $n$ and $m$, and is true independently of any excluded volume effects (since we are interested in $d \geqslant 6$ and these effects become trivial for $d \geqslant 4$ [16]). Then each active chain contributes the same constant to $T \stackrel{\circ}{S} / E^{2}$ and

$$
\Sigma \leqslant \text { const. } G \leqslant \text { const. } \delta p^{3} \quad(d=6) .
$$

Note that $\Sigma \ll \bar{\sigma}_{0 \infty}[17]$. If the variational trial function is qualitatively correct, the inequality (5) becomes an equality, and

$$
\mu(d=6)=3 \text {. }
$$

We end up with a conjecture concerning the values of $\mu$ for lower dimensions. For $p \widetilde{>} p_{c}$, after subtraction of the dangling bonds, we have a loose network with nodes $n, m$... The distance $\delta$ between neighbouring nodes diverges for $p \rightarrow p_{\mathrm{c}}$; the spatial scaling properties associated with a simple fixed point in the renormalization group [18] then impose that $\delta$ be proportional to the correlation length $\xi \sim \delta p^{-v}$. $W e$ postulate that the average number of bonds on one active chain between neighbouring nodes is $\bar{N} \sim \delta p^{-1}[19]$. Then in a field $E$ the average current through a hypersurface of area $\xi^{d-1}$ is of order

$$
\frac{\sigma}{\bar{N}}\left(V_{n}-V_{m}\right) \sim \frac{\sigma}{\bar{N}} \xi E,
$$

giving a macroscopic conductivity

$$
\Sigma \cong \delta p \xi^{2-d}=\delta p^{1+v(d-2)}
$$

For $d=3, v \sim \frac{5}{6}$ and we are led to $\mu \sim \frac{11}{6}$, not very far from the existing numerical estimates $(\mu \sim 1.5)$ [4]. For $d=2$, eq. (7) might go to a logarithmic law $\Sigma \sim \delta p / \ln (1 / \delta p)$ which is not incompatible. with the data [1], [4]. For $d=6, v=\frac{1}{2}$ (mean field value [13]). Eq. (5) and (7) are then compatible. To have a better check it would be most interesting to carry out an expansion of $\mu$ in powers of $s=6-d$.

\section{References}

[1] Last, B., Thouless, D., Phys. Rev. Lett. 27 (1971) 1719.

[2] Fortuin, C., Kastelejn, P., Physica 57 (1973) 536.

[3] Harris, A., Lubensky, T., Holcomb, W., Dasgupta, C., Phys. Rev. Lett. 35 (1975) 327.

[4] Kirkpatrick, S., Solid State Commun. 12 (1973) 1279.

[5] LAST, B., M. Sc. Thesis, Birmingham 1972.

[6] Pellan, P., Dousselin, G., Cortes, H., Rosenblatt, J., Solid State Commun. 11 (1972) 427; Deutscher, G., GeSherson, M., Grubaum, E., Imry, J., J. Vac. Sci. Technol. 10 (1973) 697.

[7] For a review of gelation properties, see for instance GoRdon, M., RGCP Plastiques 4 (1967) 111.

[8] We define $A$ through a free energy contribution $\frac{1}{2} \frac{A}{M^{2}}(\nabla \mathbf{M})^{2}$ where $M$ is the magnetization. This is related to the spin wave rigidity $D$ of ref. [4] by $A=$ const. $D M$.

[9] $\mathrm{P}_{2} \mathrm{O}_{5}$ attacked by $\mathrm{POCl}_{3}$ is an approximate example of this situation : see VAN WAZER, J. R., Phosphorus and its compounds I (Interscience London) 1958.

[10] For a theoretical discussion of polyesterifications with adipic acid, see Gordon, M., Scantelbury, G., J. Chem. Soc. B, 1 (1967).

[11] StockmaYeR, W. H., Advancing fronts in chemistry I (Reinhold N. Y.) 1945

[12] Another case where mean field behavior holds is found with vulcanization of long chains at $d>4$. See DE GeNNES, P. G., J. Physique 36 (1975) 1199.

[13] Toulouse, G., Pfeutu, P., Introduction aux groupes de renormalisation (Presses Un. Grenoble) 1975.

[14] Stinchcombe, R. B., J. Phys. C 6 L. p 1.

[15] Dobson, G. R., Gordon, M., J. Chem. Phys. 43 (1965) 705. I [16] De Gennes, P. G., Phys. Lett. 38A (1972) 339.

[17] The difference between $\bar{\sigma}_{0 \infty}$ and $\Sigma$ is not surprising, but has not been emphasized in the literature.

[18] Our notation for critical exponents follows FisHeR, M., Rep. Prog. Phys. 30 (1967) 615, Rev. Mod. Phys. 46 (1974) 597.

[19] This is correct for the tree problem (see ref. [14]. Note the difference with the total number of monomers $N_{t}$ between two neighbouring nodes (reincorporating the dangling bonds) $N_{t} \sim \delta p^{-\gamma}$. 